\title{
Surgery for Hip Fracture Yields Societal Benefits That Exceed the Direct Medical Costs
}

\author{
Qian Gu PhD, Lane Koenig PhD, Richard C. Mather III MD, \\ John Tongue MD
}

Received: 21 January 2014/ Accepted: 14 July 2014/Published online: 5 August 2014

(C) The Author(s) 2014. This article is published with open access at Springerlink.com

\begin{abstract}
Background A hip fracture is a debilitating condition that consumes significant resources in the United States. Surgical treatment of hip fractures can achieve better survival and functional outcomes than nonoperative treatment, but less is known about its economic benefits.

Questions/purposes We asked: (1) Are the societal benefits of hip fracture surgery enough to offset the direct medical costs? (2) Nationally, what are the total lifetime
\end{abstract}

One or more of the authors (QG, LK, RCM) has received or may receive, during the study period, funding from the American Academy of Orthopaedic Surgeons (Rosemont, IL, USA). All ICMJE Conflict of Interest Forms for authors and Clinical Orthopaedics and Related Research ${ }^{\mathbb{R}}$ editors and board members are on file with the publication and can be viewed on request.

Clinical Orthopaedics and Related Research ${ }^{\circledR}$ neither advocates nor endorses the use of any treatment, drug, or device. Readers are encouraged to always seek additional information, including FDA approval status, of any drug or device before clinical use.

This work was performed at KNG Health Consulting LLC, Rockville, MD, USA.

Electronic supplementary material The online version of this article (doi:10.1007/s11999-014-3820-6) contains supplementary material, which is available to authorized users.

Q. Gu

Econometrica, Inc, Bethesda, MD, USA

L. Koenig $(\bowtie)$

KNG Health Consulting LLC, 15245 Research Blvd, Suite 305,

Rockville, MD 20850, USA

e-mail: lane.koenig@knghealth.com

R. C. Mather III

Duke Orthopaedic Surgery, Durham, NC, USA

J. Tongue

Oregon Health and Science University, Tualatin, OR, USA benefits of hip fracture surgery for a cohort of patients and to whom do these benefits accrue?

Methods We estimated the effects of surgical treatment for displaced hip fractures through a Markov cohort analysis of patients 65 years and older. Assumptions were obtained from a systematic literature review, analysis of Medicare claims data, and clinical experts. We conducted a series sensitivity analyses to assess the effect of uncertainty in model parameters on our estimates. We compared costs for medical care, home modification, and long-term nursing home use for surgical and nonoperative treatment of hip fractures to estimate total societal savings.

Results Estimated average lifetime societal benefits per patient exceeded the direct medical costs of hip fracture surgery by USD 65,000 to USD 68,000 for displaced hip fractures. With the exception of the assumption of nursing home use, the sensitivity analyses show that surgery produces positive net societal savings with significant deviations of $50 \%$ from the base model assumptions. For an 80-year-old patient, the breakeven point for the assumption on the percent of patients with hip fractures who would require long-term nursing home use with nonoperative treatment is $37 \%$ to $39 \%$, compared with $24 \%$ for surgical patients. Nationally, we estimate that hip fracture surgery for the cohort of patients in 2009 yields lifetime societal savings of USD 16 billion in our base model, with benefits and direct costs of USD 21 billion and USD 5 billion, respectively. For an 80-year-old, societal benefits ranged from USD 2 billion to USD 32 billion, using our range of estimates for nursing home use among nonoperatively treated patients who are immobile after the fracture.

Conclusions Surgical treatment of hip fractures produces societal savings. Although the magnitude of these savings 
depends on model assumptions, the finding of societal savings is robust to a range of parameter values.

Level of Evidence Level III, economic and decision analyses. See the Instructions for Authors for a complete description of levels of evidence.

\section{Introduction}

More than 300,000 patients sustain a hip fracture each year in the United States [3]. These serious injuries often result in nursing home stays, increased mortality, and overall lower quality of life $[5,13,20,24,25,41]$. Hip fracture rates increase exponentially with age [34], with approximately $90 \%$ of hip fractures occurring in people older than 65 years [36]. As the US population ages, the incidence of hip fracture is expected to increase substantially. One study estimated that by 2040, the annual incidence of hip fractures will exceed 500,000 in the United States population [32]. These continuing trends will place a financial burden on patients, families, insurers, and governments.

Although surgery is the predominant treatment strategy for hip fractures because it reduces mortality risk and improves physical functioning for many patients, less is known about its societal cost implications. With policy makers and payers increasingly focused on value, it is critical to understand the return from healthcare spending. In this study, we considered the economic returns from spending on hip fracture. The broader economic effects of surgical treatment for hip fractures are reflected in direct medical costs and indirect costs, including long-term medical costs, custodian costs associated with nursing home stays, and the cost of home modification. Estimates of the societal benefits of medical treatment help establish a larger context for critically viewing overall healthcare spending, which informs health policy decision making and healthcare resource allocation.

We evaluated the economic value of surgical treatment of hip fractures for patients who undergo surgery and society in general by addressing two questions: (1) Are the societal benefits of hip fracture surgery enough to offset the direct medical costs? (2) Nationally, what are the total lifetime benefits of hip fracture surgery for a cohort of patients and to whom do these benefits accrue?

\section{Materials and Methods}

We estimated the effects of surgical treatment for displaced intracapsular and extracapsular hip fractures through a Markov cohort analysis (Fig. 1). The analysis was limited to patients 65 years and older and results were generated
Fig. 1A-B (A) A decision tree shows the treatment pathway and health states in the Markov model of hip fractures. The surgical branch of intracapsular fractures consists of four health states: dead, well, infection revision, and aseptic revision (infection and aseptic revisions are represented by one oval in the figure). In the first year after surgery, living patients enter the well state. The well state includes good and fair outcomes. For patients in the well state, they can die, stay in that health state, or have a revision surgery in the subsequent year. The nonoperative branch consists of three states: dead, survive - immobile, and survive - mobile. Once patients enter either survive - immobile or survive - mobile, they stay there until they die. (B) The surgical branch of extracapsular fractures consists of five health states: dead, well, conversion to arthroplasty, infection revision arthroplasty, and aseptic revision arthroplasty (infection and aseptic revisions are represented by one oval in the figure). The well state includes good and fair outcomes, because distribution and utility data for these separate health states were unavailable for extracapsular fracture. Patients can die, do well, or undergo conversion surgery to arthroplasty during the first year. For patients who had a conversion to arthroplasty, they can die, stay in that state, or have a revision arthroplasty in the subsequent year. The nonoperative branch consists of three states: dead, survive - immobile, and survive - mobile. Once patients enter either survive - immobile or survive - mobile, they stay there until they die.

for cohorts ranging in age from 65 to 98 years and summarized using the age distribution of patients with hip fractures who undergo surgery in the United States. Model assumptions (Table 1) were obtained from a systematic literature review, analysis of Medicare claims data, and clinical experts. We recruited and consulted a team of experts with clinical experience in surgical and postoperative care of patients with hip fractures. The expert panel consisted of three orthopaedic surgeons (JOA, RFK, DWL), two physical therapists (HR, JB), and one physical medicine and rehabilitation physician (AK). For assumptions not available in the literature (assumptions related to nonoperative treatment), we relied on the consensus reached by the clinical experts through a series of interviews and questionnaires.

We ran separate models for each of four surgical techniques: hemiarthroplasty and THA for displaced intracapsular fractures and intramedullary and extramedullary implants for extracapsular fractures. Internal fixation was not modeled for displaced intracapsular hip fractures since it is not the preferred treatment for older patients [16]. To assess the effect of uncertainty in model assumptions, we conducted a series of sensitivity analyses that tested a reasonable range of all parameters in the Markov model for a representative 80-year-old (Table 2). These sensitivity analyses show the effect of changes in each model parameter (eg, first year mortality rate) on model outputs. We also performed scenario sensitivity analyses in which multiple parameters changed simultaneously to test model outputs under more extreme conditions. The model was estimated in TreeAge Pro 2011 (TreeAge Software, Inc, Williamstown, 

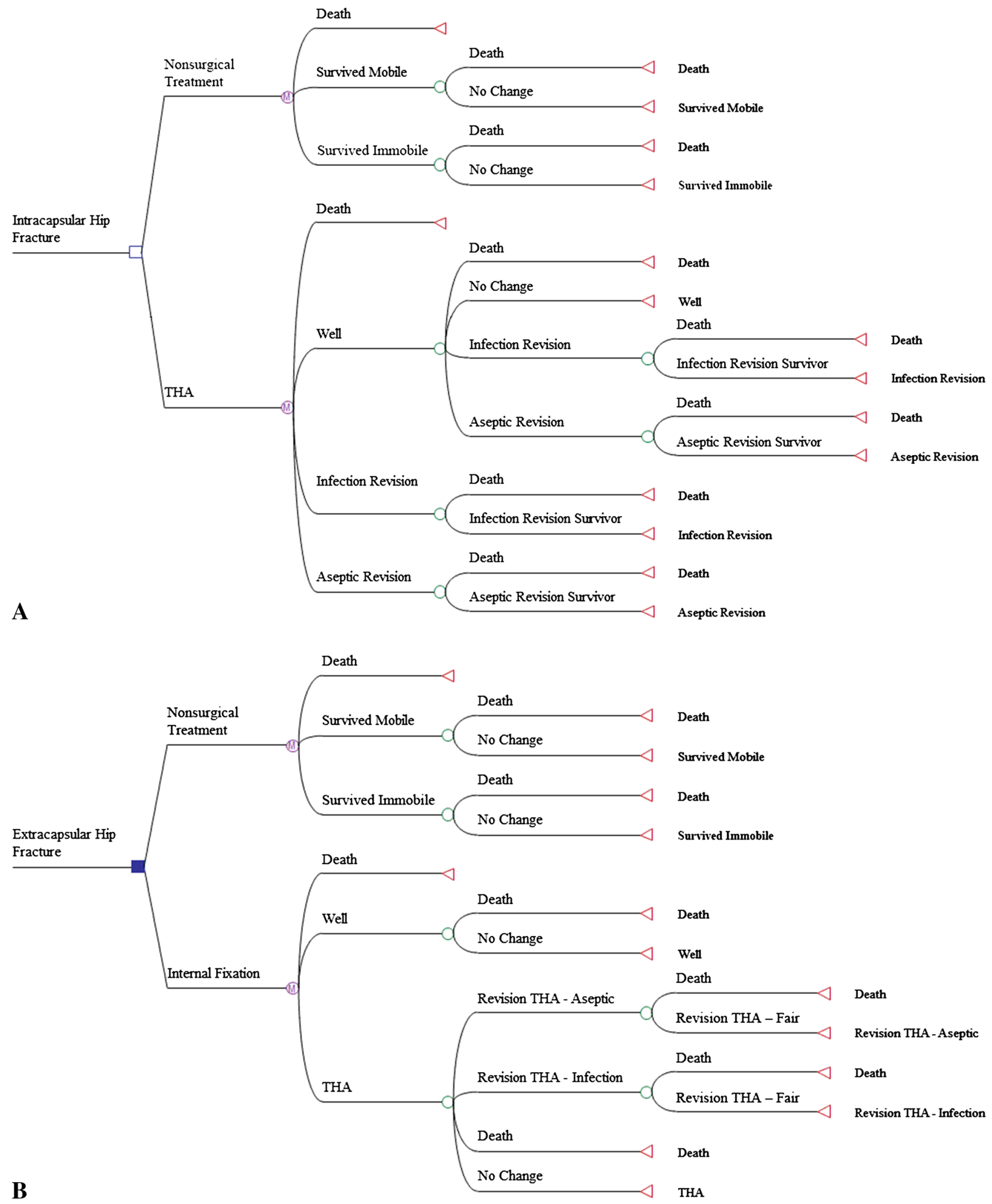

MA, USA) using the Markov model transition probability matrix. Additional details on the derivation of model assumptions and approach are provided (Appendix 1. Supplemental materials are available with the online version of
$\mathrm{CORR}^{\circledR}$ ). Specifically, Appendix 1 includes additional information regarding the use of the clinical experts, the derivation of all-payer payments, and the development of assumptions regarding long-term nursing home use. 
Table 1. Clinical parameters and utilities in base Markov model

\begin{tabular}{|c|c|c|c|c|c|c|}
\hline \multirow{2}{*}{$\begin{array}{l}\text { Clinical parameters/ } \\
\text { utilities }\end{array}$} & \multicolumn{3}{|c|}{ Displaced intracapsular fractures } & \multicolumn{3}{|c|}{ Extracapsular fractures } \\
\hline & Hemiarthroplasty & THA & Nonoperative & $\begin{array}{l}\text { Sliding hip } \\
\text { screw }\end{array}$ & Gamma nail & Nonoperative \\
\hline \multicolumn{7}{|l|}{ Clinical parameter } \\
\hline First-year mortality & $\begin{array}{l}3.07 \times \text { natural } \\
\text { mortality [13] }\end{array}$ & $\begin{array}{l}3.07 \times \text { natural } \\
\text { mortality } \\
{[13]}\end{array}$ & $\begin{array}{c}1.33 \times 3.07 \times \text { natural } \\
\text { mortality }[13,18]\end{array}$ & $\begin{array}{l}3.07 \times \text { natural } \\
\text { mortality } \\
{[13]}\end{array}$ & $\begin{array}{l}3.07 \times \text { natural } \\
\text { mortality } \\
{[13]}\end{array}$ & $\begin{array}{c}1.33 \times 3.07 \times \text { natural } \\
\text { mortality }[13,18]\end{array}$ \\
\hline $\begin{array}{l}\text { Second-year } \\
\text { mortality }\end{array}$ & $\begin{array}{l}1.87 \times \text { natural } \\
\text { mortality [13] }\end{array}$ & $\begin{array}{l}1.87 \times \text { natural } \\
\text { mortality } \\
{[13]}\end{array}$ & $\begin{array}{c}1.33 \times 1.87 \times \text { natural } \\
\text { mortality }[13,18]\end{array}$ & $\begin{array}{l}1.87 \times \text { natural } \\
\text { mortality } \\
{[13]}\end{array}$ & $\begin{array}{l}1.87 \times \text { natural } \\
\text { mortality } \\
{[13]}\end{array}$ & $\begin{array}{c}1.33 \times 1.87 \times \text { natural } \\
\text { mortality }[13,18]\end{array}$ \\
\hline $\begin{array}{l}\text { Rate of conversion } \\
\text { to arthroplasty }\end{array}$ & & & & $0.04[1]$ & $0.06[1]$ & NA \\
\hline $\begin{array}{l}\text { Annual rate of } \\
\text { revision } \\
\text { arthroplasty - } \\
\text { aseptic }\end{array}$ & $0.034[31]$ & $0.0067[31]$ & NA & $0.0067[31]$ & $0.0067[31]$ & NA \\
\hline $\begin{array}{l}\text { Annual rate of } \\
\text { revision } \\
\text { arthroplasty - } \\
\text { infection }\end{array}$ & $0.0053[31]$ & $0.0033[31]$ & NA & $0.0033[31]$ & $0.0033[31]$ & NA \\
\hline $\begin{array}{l}\text { Surgical mortality of } \\
\text { revision } \\
\text { arthroplasty - } \\
\text { aseptic }\end{array}$ & $0.012[9]$ & $0.012[9]$ & NA & $0.012[9]$ & 0.012 [9] & NA \\
\hline $\begin{array}{l}\text { Surgical mortality of } \\
\text { revision } \\
\text { arthroplasty - } \\
\text { infection }\end{array}$ & $0.0193[9]$ & $0.0193[9]$ & NA & $0.0193[9]$ & $0.0193[9]$ & NA \\
\hline $\begin{array}{l}\text { Probability of } \\
\text { mobility if survive }\end{array}$ & NA & NA & $0.5[12]$ & NA & NA & $0.5[12]$ \\
\hline \multicolumn{7}{|l|}{ Utility } \\
\hline Dead & 0 & 0 & 0 & 0 & 0 & 0 \\
\hline Well & $0.66[22]$ & $0.7[22]$ & NA & $0.54[10,27]$ & $0.54[10,27]$ & NA \\
\hline $\begin{array}{l}\text { Conversion to } \\
\text { arthroplasty }\end{array}$ & & & & $0.54[10,27]$ & $0.54[10,27]$ & NA \\
\hline $\begin{array}{l}\text { Revision } \\
\text { arthroplasty - } \\
\text { aseptic }\end{array}$ & $0.66[22]$ & $0.7[22]$ & NA & $0.54[10,27]$ & $0.54[10,27]$ & NA \\
\hline $\begin{array}{l}\text { Revision } \\
\text { arthroplasty - } \\
\text { infection }\end{array}$ & $0.39[38, \mathrm{E}]$ & $0.39[38, \mathrm{E}]$ & NA & $0.38[10, \mathrm{E}]$ & $0.38[10, \mathrm{E}]$ & NA \\
\hline Survive - mobile & NA & NA & $0.39[\mathrm{E}]$ & NA & NA & $0.38[10, \mathrm{E}]$ \\
\hline Survive - immobile & NA & NA & $0[2]$ & NA & NA & $0[2]$ \\
\hline $\begin{array}{l}\text { Disutility - internal } \\
\text { fixation }\end{array}$ & & & & $-0.15[35]$ & $-0.15[35]$ & NA \\
\hline $\begin{array}{l}\text { Disutility - initial } \\
\text { arthroplasty }\end{array}$ & $-0.15[35]$ & $-0.15[35]$ & NA & $-0.15[35]$ & $-0.15[35]$ & NA \\
\hline $\begin{array}{l}\text { Disutility - revision } \\
\text { arthroplasty }\end{array}$ & $-0.2[35]$ & $-0.2[35]$ & NA & $-0.2[35]$ & $-0.2[35]$ & NA \\
\hline
\end{tabular}

Numbers in brackets indicate the source of information (ie, reference number of studies cited); $\mathrm{E}=$ expert opinion; NA $=$ results not affected by parameter. 


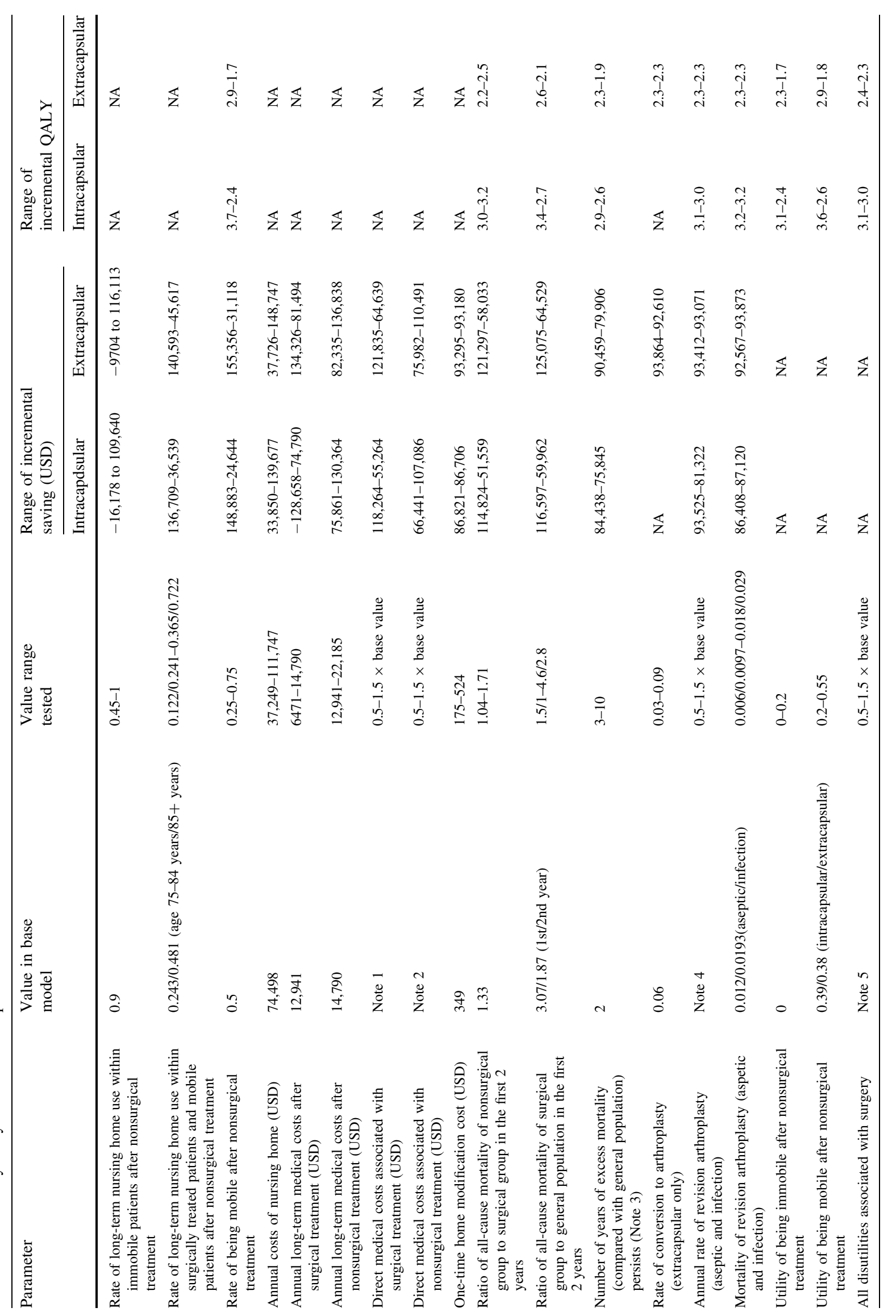




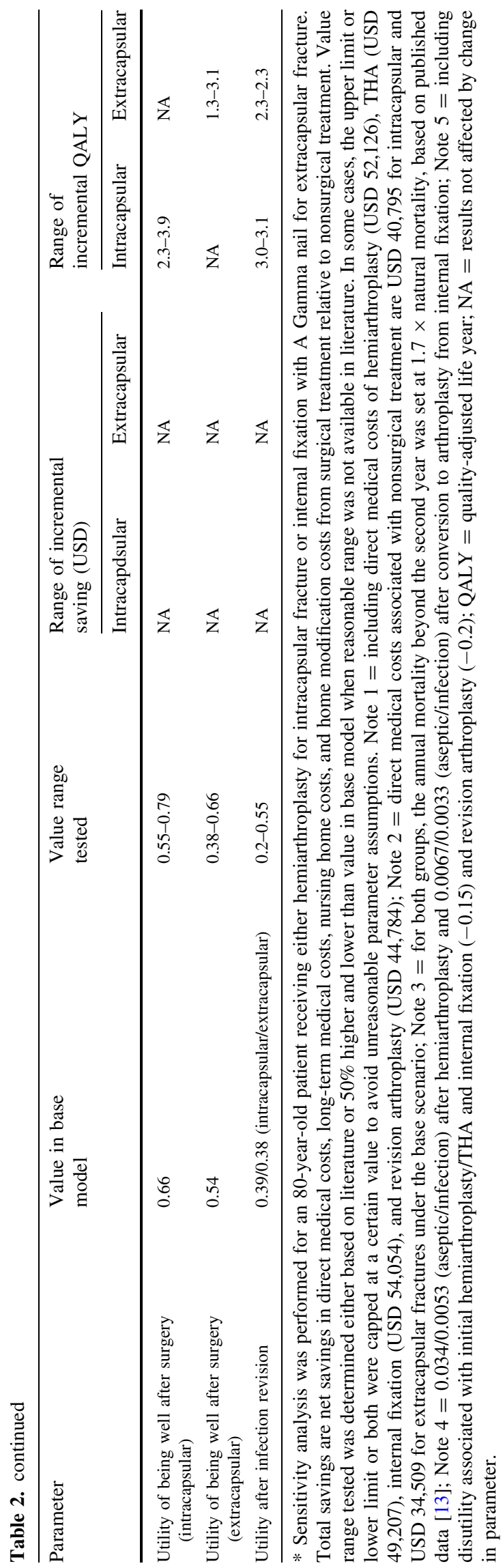

Clinical Parameters

Mortality rates after hip fracture vary [11, 20, 22, 29, 33, $39,40]$; we assumed overall relative risks of 3.07 and 1.87 during the first and second years after a hip fracture, with a subsequent return to age-specific levels [13]. These values then were applied to the age-specific natural mortality in the US life tables [4]. For revision, we used the surgical mortality rate of infection revision (1.2\%) and aseptic revision (1.9\%) reported by Chang et al. [9] for hemiarthroplasty and THA.

Few studies report mortality rates for nonoperative treatment of hip fractures [14, 18, 19, 28]. We used the existing literature to set the mortality rate equal to 1.33 times the mortality rate of patients treated surgically [18]. After the second year, we used the age-specific natural mortality level for surgical and nonsurgical groups.

The long-term revision rate reported by Ravikumar and Marsh [31] was used to estimate the rates for septic and aseptic revision for intracapsular fracture.

For revision of extracapsular fracture treatment, we used first-year revision rates as reported by Adam et al. [1], of $4 \%$ and $6 \%$ for patients treated with sliding hip screws and intramedullary nails, respectively. We assumed that all patients who needed a reoperation to treat failed internal fixation received a conversion to THA within the first year. For revision rates in subsequent years, we used the intracapsular revision rate that reflects revisions after THA. For both types of hip fractures, we allowed no more than one revision arthroplasty.

The utility values for the health states represented in the model were attained from a review of the literature. The utility values are used to estimate the QualityAdjusted Life Years (QALYs), which is a standard metric to measure patient quality of life. QALY is the product of the number of additional years to live as a result of a treatment and the utility of the patient health status in those years, with utility usually ranging from 0 for death to 1 for perfect health. For example, if a treatment extends a patient's life by 2 years and the utility of patient health status after treatment is 0.8 , we would say that treatment leads to an additional 1.6 (ie, $2 * 0.8)$ QALYs. For the intracapsular and extracapsular models, we used a one-time disutility of -0.15 for arthroplasty and internal fixation and -0.2 for revision arthroplasty [35].

Based on the available literature, we assumed that $50 \%$ of the patients who are treated nonoperatively for displaced intracapsular and extracapsular fractures can walk at the conclusion of treatment. For both types of fractures, we set a utility level of 0 for survivors of nonsurgical treatment who cannot walk, based on our estimate using the US valuation of EQ-5D ${ }^{\mathrm{TM}}$ [2]. For patients who can mobilize 
after treatment, their utility was set to be the same as the utility after infection revision based on expert opinion.

\section{Nursing Home Utilization}

We developed estimates of the probability of being in a nursing home before and after a hip fracture using findings from the literature [6, 37], the 2004 National Nursing Home Survey [21], and clinical expert input. The following assumptions were made regarding nursing home use for patients with hip fractures: (1) rates of long-term nursing home use for patients treated surgically and for patients who obtain mobility after nonsurgical treatment of a hip fracture are $16 \%$ for patients 65 to 74 years old, $24 \%$ for patients 75 to 84 years old, and $48 \%$ for patients older than 85 years; and (2) rates of long-term nursing home use for patients treated nonsurgically and immobile are $53 \%$ for patients 65 to 74 years old, $57 \%$ for patients 75 to 84 years old, and $69 \%$ for patients older than 85 years (Appendix 1. Supplemental material is available with the online version of $\left.\mathrm{CORR}^{\circledR}\right)$.

\section{Cost Estimates}

Estimates of the direct medical costs (which include inpatient, postacute care, rehabilitation, outpatient, and physician services, but exclude long-term nursing home costs) associated with surgical and nonsurgical treatment (Table 3) were derived from a payer perspective and based on claims for a $5 \%$ sample of Medicare beneficiaries in 2009 but adjusted to reflect all payer costs. We accumulated medical costs incurred from hospitalization for hip fracture to 6 months after the hospital discharge from Medicare claims. Long-term (ie, beyond 6 months) annual medical costs are likely to be higher in the nonoperative group than in the surgical group because of increased functional limitations [14]. Based on literature [7, 8, 14] and expert opinion, we assumed long-term annual healthcare costs of USD 12,941 for surgically treated patients and USD 14,790 for nonoperatively treated patients. We assumed an annual nursing home cost of USD 74,498 (2009 USD) based on the 2011 MetLife Market Survey of Nursing Homes [26] and a one-time home modification cost of USD 349 based on our estimates using the 2010 Health and Retirement Study [15].

\section{Results}

Are the societal benefits of hip fracture surgery enough to offset the direct medical costs? We estimated that the lifetime benefits to society from surgical treatment of hip
Table 3. Average direct medical costs for 6 months after hip fractures

\begin{tabular}{lll}
\hline Type of fracture & Treatment & $\begin{array}{l}\text { Average direct } \\
\text { medical cost (USD)* }\end{array}$ \\
\hline Intracapsular & Hemiarthroplasty & 52,126 \\
Intracapsular & THA & 49,207 \\
Intracapsular & Nonsurgical treatment & 40,795 \\
Extracapsular & Internal fixation & 54,054 \\
Extracapsular & Nonsurgical treatment & 34,509 \\
Both & Revision hip arthroplasty & 44,784
\end{tabular}

We analyzed 5\% sample of 2009 Medicare inpatient claims; ICD-9 diagnosis codes $820.0 \mathrm{x}$ and $820.1 \mathrm{x}$ were used to identify patients with intracapsular fractures and $820.2 \mathrm{x}$ and $820.3 \mathrm{x}$ for extracapsular fractures. The following ICD-9 procedure codes were used to identify relevant procedures: 81.51 (THA), 81.52 (hemiarthroplasty), 79.35 (open reduction and internal fixation), 81.53 and 00.70 to 00.73 (revision hip arthroplasty); *cost estimates were risk-standardized for age, sex, and comorbidities and adjusted to reflect different reimbursement rates across payers (eg, private, Medicare, Medicaid, selfinsured, and uninsured); estimates include all medical costs (facility and physician fees) across all care settings (including readmissions to hospital, outpatient, and postacute care facilities) from the index hospitalization to 6 months after discharge from the index hospitalization; all costs are expressed in 2009 USD.

fracture more than offset the direct medical costs, with average savings per patient of USD 65,279 and USD 67,964 for displaced intracapsular and extracapsular hip fractures, respectively (Table 4). For displaced intracapsular fractures, the surgical treatment cost USD 19,710 more than nonoperative treatment, which was offset by savings of USD 84,990 from lower long-term medical costs and reduced nursing home use. For extracapsular fractures, the direct medical costs for surgical treatment were USD 22,317 higher than that of nonoperative treatment but were offset by savings of USD 90,281. We estimated that the surgical treatment of hip fractures produced an average increase of 2.5 quality-adjusted life years (QALYs) for patients with intracapsular fractures and 1.9 QALYs for patients with extracapsular fracture (Table 4). Surgical treatment was a dominant treatment strategy for hip fracture when total societal savings were considered because it achieved better quality of life at lower cost.

For both types of hip fractures, total societal savings and increased QALYs from surgical treatments varied considerably across age groups (Table 4). For example, surgical treatment for an intracapsular fracture achieved approximately USD 160,000 in societal savings and 4.2 QALYs per patient for patients 70 to 79 years old. For patients older than 90 years, surgical treatment was more expensive although still cost-effective.

Because avoided nursing home costs accounted for most of the savings, the results were most sensitive to 
Table 4. Societal savings and additional QALYs from surgical treatment of hip fractures

\begin{tabular}{|c|c|c|c|c|c|c|c|}
\hline \multirow{2}{*}{$\begin{array}{l}\text { Age } \\
\text { group }\end{array}$} & \multicolumn{5}{|c|}{ Societal savings ( $\Delta \mathrm{USD}^{*}$ surgical relative to nonsurgical) } & \multirow{2}{*}{$\begin{array}{l}\Delta \\
\text { QALY } \\
\text { F }\end{array}$} & \multirow{2}{*}{$\begin{array}{l}\text { ICER }\left(\Delta \text { USD }^{*}\right. \\
\Delta \text { QALY }) \\
\text { E/F }\end{array}$} \\
\hline & $\begin{array}{l}\text { From direct } \\
\text { medical costs } \\
\text { A }\end{array}$ & $\begin{array}{l}\text { From long-term } \\
\text { medical costs } \\
\text { B }\end{array}$ & $\begin{array}{l}\text { From nursing } \\
\text { home costs } \\
\text { C }\end{array}$ & $\begin{array}{l}\text { From home } \\
\text { modification costs } \\
\text { D }\end{array}$ & $\begin{array}{l}\text { Total } \\
\text { savings } \\
\mathrm{E}\end{array}$ & & \\
\hline \multicolumn{8}{|c|}{ Intracapsular fractures } \\
\hline $\begin{array}{r}65-69 \\
\text { years }\end{array}$ & $-28,006$ & 18,811 & 312,781 & -129 & 303,458 & 6.1 & Dominant \\
\hline $\begin{array}{r}70-79 \\
\text { years }\end{array}$ & $-23,941$ & 8993 & 176,688 & -120 & 161,620 & 4.2 & Dominant \\
\hline $\begin{array}{r}80-89 \\
\text { years }\end{array}$ & $-18,914$ & -705 & 49,635 & -93 & 29,923 & 2.2 & Dominant \\
\hline $\begin{array}{l}90+ \\
\text { years }\end{array}$ & $-14,896$ & -3336 & 5905 & -73 & $-12,400$ & 0.8 & 19,544 \\
\hline Overall & $-19,710$ & 1969 & 83,118 & -97 & 65,279 & 2.5 & Dominant \\
\hline \multicolumn{8}{|c|}{ Extracapsular fractures } \\
\hline $\begin{array}{r}65-69 \\
\text { years }\end{array}$ & $-22,447$ & 21,451 & 318,329 & -129 & 317,203 & 4.6 & Dominant \\
\hline $\begin{array}{r}70-79 \\
\text { years }\end{array}$ & $-22,380$ & 10,901 & 181,982 & -120 & 170,383 & 3.1 & Dominant \\
\hline $\begin{array}{r}80-89 \\
\text { years }\end{array}$ & $-22,305$ & 378 & 53,922 & -93 & 31,902 & 1.6 & Dominant \\
\hline $90+$ & $-22,244$ & -2892 & 7675 & -73 & $-17,533$ & 0.6 & 37,073 \\
\hline Overall & $-22,317$ & 3190 & 87,188 & -97 & 67,964 & 1.9 & Dominant \\
\hline
\end{tabular}

Values are estimated relative to nonsurgical treatments; Column E is calculated as the sum of columns A through D; negative values in E (negative savings) represent increases in societal costs; savings by age groups were weighted by age distribution of the patient population to reach overall savings; all savings are expressed in 2009 USD; QALY = quality-adjusted life year; ICER = incremental cost-effectiveness ratio, calculated using differences in total costs.

changes in the parameters related to nursing home use. For an 80-year-old, the breakeven point for the assumption on the percent of patients with hip fractures who would require long-term nursing home use with nonoperative treatment is $37 \%$ to $39 \%$, as compared with $24 \%$ for surgical patients. That is, avoided nursing home costs would offset the increased cost of surgery for hip fracture when the probability of requiring nursing home use is $13 \%$ to $15 \%$ higher with nonoperative treatment than with surgical treatment. For all other parameters, the sensitivity analysis showed that surgery always produced a positive net societal savings even with significant deviations (eg, 50\%) from the base model assumptions (Table 2). We also performed scenario sensitivity analyses by changing multiple parameters simultaneously to test the robustness of our estimates under more extreme scenarios (Appendix 1. Supplemental materials are available with the online version of $\mathrm{CORR}^{\mathbb{R}}$ ). Overall, our saving estimates were relatively robust to parameter assumptions. The QALY estimates were relatively sensitive to the utility of being well after surgery to treat extracapsular fractures.

Nationally, what are the total lifetime benefits of hip fracture surgery for a cohort of patients and to whom do these benefits accrue? At the national level, our findings suggested societal savings from surgical treatment of hip fractures of USD 16 billion for elderly patients in 2009 (based on 307,538 hospital discharges in the United States [3], 90\% occurring in patients 65 years or older [36], 1/2 being extracapsular fractures [12], and $85 \%$ of intracapsular fractures displaced [30]). The lifetime total societal benefits from surgical treatment of hip fractures were approximately USD 21 billion with direct medical costs of USD 5 billion. Almost all the benefits (>95\%) were from avoided nursing home costs, which largely accrued to state Medicaid programs and patients. The remaining benefits came from lower long-term medical spending, which largely accrued to government payers (Medicare and Medicaid). As with our individual-level estimates, the national savings estimates are sensitive to the assumption of nursing home use under the nonoperative treatment scenario. Using the range of assumptions for rate of longterm nursing home use among immobile patients after nonsurgical treatment (Table 2), we estimate that societal benefits at the national level range from USD 2 billion to USD 32 billion, with societal savings ranging from USD -3 billion (USD 2 billion to 5 billion) to USD 27 billion (USD 32 billion to 5 billion). Thus, in our most 
conservative estimate, surgical treatment of hip fracture yields reduced nursing home costs that offset almost $40 \%$ of the additional cost of surgery $(0.4=2$ billion $/ 5$ billion $)$.

\section{Discussion}

Surgical treatment is considered standard of care for the majority of patients with hip fractures, but evidence regarding the value of surgical treatment of these fractures from a societal perspective is missing in the current literature. In this study, we used a Markov model to assess cost and benefit from operative treatment. We sought to determine whether: (1) the societal benefits of hip fracture surgery are enough to offset the direct medical costs, and (2) the total lifetime benefits of hip fracture surgery for a cohort of patients and to whom these benefits accrue.

The primary limitations of the study occur because of a lack of high-quality data regarding outcomes for nonsurgical treatment of hip fractures. The assumption regarding nursing home use among immobile patients (ie, 90\%) is especially important since most of the societal savings were from avoidance of prolonged use of nursing homes. To develop assumptions regarding outcomes under the nonoperative treatment scenario, we relied on a small number of studies and expert opinion. We similarly developed assumptions regarding number of activities of daily living for patients with hip fractures who do not receive surgery and then relied on literature associating healthcare spending with number of activities of daily living. To address the potential effects of bias on the study conclusions from gaps in the data, we conducted extensive sensitivity analyses, which revealed savings even under assumptions more favorable to nonsurgical treatment. There are two additional potential limitations. First, patients undergoing surgery may be healthier at the outset than patients who are treated nonoperatively; thus, difference in outcomes observed in the literature could be influenced by treatment selection. Second, since the 5\% Medicare dataset we used to estimate costs includes few patients younger than 65 years, we cannot necessarily extrapolate the results here to younger patients.

We estimated age-weighted, lifetime savings to society for surgical treatment of hip fractures to be more than USD 65,000 per patient, with surgical treatment of hip fractures producing 2.5 and 1.9 additional QALYs compared with nonsurgical treatment for displaced intracapsular and extracapsular hip fractures, respectively. Almost all of the societal savings from surgical treatment of hip fracture were from avoided nursing home costs. Although there are no comparable studies in the literature showing the value of surgical treatment for hip fractures, studies have documented the high personal and financial cost of hip fracture.
Braithwaite et al. [6] estimated that a hip fracture reduces life expectancy by 1.8 years with the lifetime cost of a hip fracture at USD 81,300 (1997 dollars). Approximately 44\% of these costs were associated with nursing facility expenses. Other studies have documented substantial reductions in functional status with hip fractures $[5,6,10$, $12,17,24,41]$. Consistent with our findings of savings from surgical treatment, studies of nonoperative treatment for hip fractures, while limited, report high rates of immobility (45\%) [12] and dependency (29\% of surgically treated patients versus 57\% nonoperatively treated) [18].

At the national level, our findings suggested substantial societal savings from surgical treatment of hip fractures. We estimated that the lifetime total societal savings from surgical treatment of hip fractures was USD 16 billion for elderly patients treated in 2009 , mainly from avoidance of nursing home costs. By comparison, Braithwaite et al. [6] estimated lifetime cost for all hip fractures in the US of at least USD 20 billion. Thus, while hip fractures impose substantial societal costs, the results show that surgery has an important role in minimizing the societal burden of hip fractures.

Our study is the first to our knowledge to quantify the economic value of surgical treatment of hip fractures in terms of reduced lifetime societal costs. The scope of factors considered for the calculation of value extended beyond direct medical treatment costs to the long-term medical costs associated with impaired functioning and to nursing home costs accumulated during a lifetime. Although the magnitude of the societal savings depends on model assumptions, the finding of societal savings is robust to a range of parameter values. Because the study focused on the cohort of patients receiving surgery, our results should not be interpreted as suggesting that surgery is appropriate for all patients with hip fractures. This analysis, however, serves as an important benchmark for the economic value of surgery for hip fractures. The method used in our study can be used in future studies to show the additional economic effects as hip fracture care is improved. Future studies also might consider that additional benefits to society from improved employment and productivity resulted from successful surgical treatment of hip fractures, as more elderly workers choose to stay in the labor force longer [23].

Acknowledgments We thank the American Academy of Orthopaedic Surgeons Value Project Team for their valuable comments on earlier drafts of the paper. We also acknowledge the clinical experts who provided critical input on our model assumptions: Jeffrey $\mathrm{O}$. Anglen MD (Department of Orthopaedics, Indiana University School of Medicine, Indianapolis, IN), Richard F. Kyle MD (Orthopaedic Surgery, University of Minnesota, Minneapolis, MN), Douglas W. Lundy MD, MBA, FACS (Orthopaedic Trauma Surgery, Resurgens Orthopaedics, Atlanta, Georgia); Heather Rositas PT, DPT and Judy Baum PT, MSHA (Mountain Valley Regional Rehabilitation 
Hospital, Prescott Valley, AZ); and Adam Kafka MD (Physical Medicine and Rehabilitation, Madonna Rehabilitation Hospital, Lincoln, NE).

Open Access This article is distributed under the terms of the Creative Commons Attribution License which permits any use, distribution, and reproduction in any medium, provided the original author(s) and the source are credited.

\section{References}

1. Adams CI, Robinson CM, Court-Brown CM, McQueen MM. Prospective randomized controlled trial of an intramedullary nail versus dynamic screw and plate for intertrochanteric fractures of the femur. J Orthop Trauma. 2001;15:394-400.

2. Agency for Healthcare Research and Quality. Calculating the U.S. population-based EQ-5D ${ }^{\mathrm{TM}}$ index score. Available at: http:// www.ahrq.gov/rice/EQ5Dscore.htm. Accessed April 23, 2012.

3. Agency for Healthcare Research and Quality. National and regional estimates on hospital use for all patients from the HCUP Nationwide Inpatient Sample (NIS). Available at: http://hcupnet. ahrq.gov/HCUPnet.jsp. Accessed July 26, 2012.

4. Arias E. United States life tables, 2007. Natl Vital Stat Rep. 2011;59:1-60.

5. Bentler S, Liu L, Obrizan M, Cook EA, Wright KB, Geweke JF, Chrischilles EA, Pavlik CE, Wallace RB, Ohsfeldt RL, Jones MP, Rosenthal GE, Wolinsky FD. The aftermath of hip fracture: discharge placement, functional status change, and mortality. Am J Epidemiol. 2009;170:1290-1299.

6. Braithwaite RS, Col NF, Wong JB. Estimating hip fracture morbidity, mortality and costs. J Am Geriatr Soc. 2003;51:364-370.

7. Centers for Medicare and Medicaid Services. Market Basket Data. Available at: http://www.cms.gov/Research-Statistics-Dataand-Systems/Statistics-Trends-and-Reports/MedicareProgram RatesStats/MarketBasketData.html. Accessed July 20, 2012.

8. Chan L, Beaver S, MacLehose RF, Jha A, Maciejewski M, Doctor JN. Disability and health care costs in the Medicare population. Arch Phys Med Rehabil. 2002;83:1196-1201.

9. Chang RW, Pellissier JM, Hazen G. A cost-effectiveness analysis of total hip arthroplasty for osteoarthritis of the hip. JAMA. 1996;275:858-865.

10. Ekström W, Miedel R, Ponzer S, Hedström M, Samnegård E, Tidermark J. Quality of life after a stable trochanteric fracture: a prospective cohort study on 148 patients. J Orthop Trauma. 2009;23:39-44.

11. Giversen IM. Time trends of mortality after first hip fractures. Osteoporos Int. 2007;18:721-732.

12. Gregory JJ, Kostakopoulou K, Cool WP, Ford DJ. One-year outcome for elderly patients with displaced intracapsular fractures of the femoral neck managed non-operatively. Injury. 2010;41:1273-1276.

13. Haentjens P, Magaziner J, Colón-Emeric CS, Vanderschueren D, Milisen K, Velkeniers B, Boonen S. Meta-analysis: excess mortality after hip fracture among older women and men. Ann Intern Med. 2010;152:380-390.

14. Handoll HH, Parker MJ. Conservative versus operative treatment for hip fractures in adults. Cochrane Database Syst Rev. 2008;3:CD000337.

15. Health and Retirement Study, 2010 Final Release public use dataset. Produced and distributed by the University of Michigan with funding from the National Institute on Aging (grant number NIA U01AG009740). Ann Arbor, MI. http://hrsonline.isr.umich. edu. Accessed July 20, 2012.
16. Heetveld MJ, Rogmark C, Frihagen F, Keating J. Internal fixation versus arthroplasty for displaced femoral neck fractures: what is the evidence? J Orthop Trauma. 2009;23:395-402.

17. Holt G, Smith R, Duncan K, Hutchison JD, Gregori A. Gender differences in epidemiology and outcome after hip fracture: evidence from the Scottish Hip Fracture Audit. J Bone Joint Surg Br. 2008;90:480-483.

18. Hossain M, Neelapala V, Andrew JG. Results of non-operative treatment following hip fracture compared to surgical intervention. Injury. 2009;40:418-421.

19. Jain R, Basinski A, Kreder HJ. Nonoperative treatment of hip fractures. Int Orthop. 2003;27:11-17.

20. Johnston AT, Barnsdale L, Smith R, Duncan K, Hutchison JD. Change in long-term mortality associated with fractures of the hip: evidence from the Scottish hip fracture audit. J Bone Joint Surg Br. 2010;92:989-993.

21. Jones AL, Dwyer LL, Bercovitz AR, Strahan GW. The National Nursing Home Survey: 2004 Overview. Vital Health Statistics. National Center for Health Statistics, Hyattsville, MD. Available at: http://www.cdc.gov/nchs/data/series/sr_13/sr13 167.pdf. Accessed May 27, 2014.

22. Keating JF, Grant A, Masson M, Scott NW, Forbes JF. Randomized comparison of reduction and fixation, bipolar hemiarthroplasty, and total hip arthroplasty: treatment of displaced intracapsular hip fractures in healthy older patients. J Bone Joint Surg Am. 2006;88:249-260.

23. Maestas N. Back to work: expectations and realizations of work after retirement. J Hum Resour. 2010;45:718-748.

24. Magaziner J, Hawkes W, Hebel JR, Zimmerman SI, Fox KM, Dolan M, Felsenthal G, Kenzora J. Recovery from hip fracture in eight areas of function. J Gerontol A Biol Sci Med Sci. 2000;55:M498-M507.

25. Marks R, Allegrante JP, Ronald MacKenzie C, Lane JM. Hip fractures among the elderly: causes, consequences and control. Ageing Res Rev. 2003;2:57-93.

26. MetLife Mature Market Institute. Market Survey of Long-Term Care Costs. The 2011 MetLife Market Survey of Nursing Home, Assisted Living, Adult Day Services, and Home Care Costs. New York, NY: MetLife Mature Market Institute; October 2011.

27. Miedel R, Ponzer S, Törnkvist H, Söderqvist A, Tidermark J. The standard Gamma nail or the Medoff sliding plate for unstable trochanteric and subtrochanteric fractures. A randomised, controlled trial. J Bone Joint Surg Br. 2005;87:68-75.

28. Ooi LH, Wong TH, Toh CL, Wong HP. Hip fractures in nonagenarians: a study on operative and non-operative management. Injury. 2005;36:142-147.

29. Parker MJ, Handoll HH. Gamma and other cephalocondylic intramedullary nails versus extramedullary implants for extracapsular hip fractures in adults. Cochrane Database Syst Rev. 2010;9:CD000093.

30. Raaymakers EL, Marti RK. Non-operative treatment of impacted femoral neck fractures: a prospective study of 170 cases. J Bone Joint Surg Br. 1991;73:950-954.

31. Ravikumar KJ, Marsh G. Internal fixation versus hemiarthroplasty versus total hip arthroplasty for displaced subcapital fracture of femur: 13 year results of a prospective randomised study. Injury. 2000;31:793-797.

32. Schneider EL, Guralnik JM. The aging of America: impact on health care costs. JAMA. 1990;263:2335-2340.

33. Schrøder HM, Erlandsen M. Age and sex as determinants of mortality after hip fracture: 3,895 patients followed for 2.518.5 years. J Orthop Trauma. 1993;7:525-531.

34. Scott JC. Osteoporosis and hip fractures. Rheum Dis Clin North Am. 1990;16:717-740.

35. Slover J, Hoffman MV, Malchau H, Tosteson AN, Koval KJ. A cost-effectiveness analysis of the arthroplasty options for 
displaced femoral neck fractures in active, healthy, elderly population. J Arthroplasty. 2009;24:854-860.

36. Stevens JA, Olson S. Reducing falls and resulting hip fractures among older women. MMWR Recomm Rep. 2000;49:3-12.

37. Sugarman JR, Connell FA, Hansen A, Helgerson SD, Jessup MC, Lee H. Hip fracture incidence in nursing home residents and community-dwelling older people, Washington State, 19931995. J Am Geriatr Soc. 2002;50:1638-1643.

38. Tidermark J, Bergström G, Svensson O, Törnkvist H, Ponzer S. Responsiveness of the EuroQol (EQ 5-D) and the SF-36 in elderly patients with displaced femoral neck fractures. Qual Life Res. 2003;12:1069-1079.
39. Tosteson A, Gottlieb D, Radley D, Fisher ES, Melton LJ 3rd. Excess mortality following hip fracture: the role of underlying health status. Osteoporos Int. 2007;18:1463-1472.

40. van den Bekerom MP, Hilverdink EF, Sierevelt IN, Reuling EM, Schnater JM, Bonke H, Goslings JC, van Dijk CN, Raaymakers EL. A comparison of hemiarthroplasty with total hip replacement for displaced intracapsular fracture of the femoral neck: a randomised controlled multicentre trial in patients aged 70 years and over. J Bone Joint Surg Br. 2010;92:1422-1428.

41. Wolinsky FD, Fitzgerald JF, Stump TE. The effect of hip fracture on mortality, hospitalization, and functional status: a prospective study. Am J Public Health. 1997;87:398-403. 